\title{
O Novo Regulamento Geral Sobre a Protecção de Dados e as Suas Implicações Quanto a Pedidos de Informação Dirigidos aos Profissionais de Saúde
}

\section{The New General Data Protection Regulation and Its Implications Regarding Clinical Information Requests to Healthcare Professionals}

\author{
Henrique PRATA RIBEIRO $\varangle^{1,2,3}$, André PONTE ${ }^{1,2}$, Francisca ROBALO CORDEIRO ${ }^{4}$, Fernando VIEIRA ${ }^{1}$ \\ Acta Med Port 2020 Apr;33(4):221-224 - https://doi.org/10.20344/amp.13162
}

Palavras-chave: Confidencialidade; Consentimento Informado; Registos Médicos; Registos de Saúde Pessoal

Keywords: Confidentiality; Informed Consent; Health Records, Personal; Medical Records

O Regulamento Geral da Proteção de Dados (RGPD), ${ }^{1}$ que entrou em vigência no dia 25 de maio de 2018, tem como objetivo estabelecer as regras relativas à proteção das pessoas singulares no que diz respeito ao tratamento de dados pessoais e à livre circulação desses dados, defendendo os direitos e as liberdades fundamentais destas pessoas.

Assim, para que se compreenda a temática abordada no presente artigo, importa atentar em duas definições cruciais e transversais a toda a matéria relacionada com a proteção de dados pessoais.

Por 'dados pessoais', entende-se a 'informação relativa a uma pessoa singular identificada ou identificável («titular dos dados»); é considerada identificável uma pessoa singular que possa ser identificada, direta ou indiretamente, em especial por referência a um identificador, como por exemplo um nome, um número de identificação, dados de localização, identificadores por via eletrónica ou a um ou mais elementos específicos da identidade física, fisiológica, genética, mental, económica, cultural ou social dessa pessoa singular". 1

Já por tratamento de dados pessoais, o RGPD refere-se a "uma operação ou um conjunto de operações efetuadas sobre dados pessoais ou sobre conjuntos de dados pessoais, por meios automatizados ou não automatizados, tais como a recolha, o registo, a organização, a estruturação, a conservação, a adaptação ou alteração, a recuperação, a consulta, a utilização, a divulgação por transmissão, difusão ou qualquer outra forma de disponibilização, a comparação ou interconexão, a limitação, o apagamento ou a destruição". ${ }^{1}$

É inegável que o RGPD veio suscitar diversas dúvidas no quotidiano da prática médica, mostrando-se, por isso, importante refletir sobre algumas questões relacionadas com essa prática, especialmente no que concerne aos pedidos de informação dirigidos pelos titulares dos dados pessoais e às obrigações legais a que os serviços de saúde se encontram adstritos.

Pretende-se, com este artigo, clarificar qual deverá ser a atuação dos médicos e/ou dos serviços administrativos de saúde no tratamento de dados de saúde dos respetivos doentes, em situações nas quais os próprios doentes lhes dirijam pedidos de acesso específicos relacionados com os seus dados pessoais, dos quais não são exceção os de natureza clínico-assistencial; ou em situações nas quais exista uma obrigação legal, perante determinadas entidades administrativas (e.g. Autoridade Tributária, Segurança Social), ou perante os Tribunais e o Ministério Público (MP). Almeja-se ainda tentar perceber como é que tais pedidos e obrigações poderão levar à tendência errada de se vir a alterar a forma e conteúdo dos registos semiológicos médicos, a uma abordagem condicionada dos próprios médicos perante os doentes, e, em última análise, e de forma não consciente, até mesmo as decisões terapêuticas.

O RGPD determina, que os dados pessoais que the dizem respeito sejam objeto de tratamento. ${ }^{1}$ Mais ainda, determina que estes sejam recolhidos para finalidades determinadas, explícitas e legítimas, não podendo ser tratados posteriormente de uma forma incompatível com essas finalidades. ${ }^{1}$ Dos princípios do RGPD, também consta ainda que os dados pessoais são objeto de um tratamento lícito e transparente em relação ao seu titular. ${ }^{1}$

Estes princípios gerais podem, numa primeira análise superficial, fazer temer pelo futuro da prática clinica e mesmo da pesquisa científica e do ensino médico. No entanto, importa referir que o RGPD prevê, no seu artigo $89^{\circ}$, garantias e derrogações (aqui com significado de revogação/ abolição) para fins de interesse público, investigação ou estatísticos, atendendo, no entanto, ao respeito pelo princípio da minimização dos dados. ${ }^{1}$ Esta minimização dos dados

1. Hospital Júlio de Matos. Centro Hospitalar Psiquiátrico de Lisboa. Lisboa. Portugal.

2. Clínica Universitária de Psiquiatria e Psicologia Médica. Faculdade de Medicina. Universidade de Lisboa. Lisboa. Portugal.

3. Deputado da iniciativa Health Parliament Portugal 2020. Lisboa. Portugal.

4. Sociedade Morais Leitão Galvão Teles Soares da Silva \& Associados. Lisboa. Portugal.

$\triangle$ Autor correspondente: Henrique Prata Ribeiro. henriqueprata@gmail.com

Recebido: 19 de novembro de 2019 - Aceite: 20 de janeiro de 2020 | Copyright @ Ordem dos Médicos 2020 
consiste em garantir que estes são adequados, pertinentes e limitados ao que é necessário relativamente às finalidades para as quais são tratados. ${ }^{1}$ Este artigo parece respeitar o parecer da Comissão Nacional de Proteção de Dados, embora este se possa considerar algo crítico, referindo que é seu entendimento que "os regimes legais nacionais admitidos pelo artigo $89 .^{\circ}$ do RGPD têm de conter normas densificadas e específicas, que traduzam uma efetiva ponderação entre cada um dos interesses em vista e os direitos fundamentais dos titulares dos dados, com previsão de medidas técnicas e organizativas que para cada tipo de finalidade se revelem adequadas à salvaguarda do direito à proteção de dados pessoais e com previsão das condições para o exercício dos direitos dos titulares dos dados previstos no RGPD na medida em que eventuais derrogações se revelem imprescindíveis para assegurar a prossecução de cada tipo de finalidade". ${ }^{2}$

A licitude do tratamento dos dados refere que o tratamento (de dados) só é válido se houver consentimento dado pelo titular; o tratamento for necessário para a execução de um contrato no qual o titular dos dados é parte ou para diligências pré-contratuais a pedido do titular dos dados; o tratamento for necessário para o cumprimento de uma obrigação jurídica a que o responsável pelo tratamento esteja sujeito; o tratamento for necessário para a defesa de interesses vitais do titular dos dados ou de outra pessoa singular; o tratamento for necessário ao exercício de funções de interesse público ou ao exercício da autoridade pública de que está investido o responsável pelo tratamento; o tratamento for necessário para efeito dos interesses legítimos prosseguidos pelo responsável pelo tratamento ou por terceiros, exceto se prevalecerem os interesses ou direitos e liberdades fundamentais do titular que exijam a proteção dos dados pessoais, em especial se o titular for uma criança. ${ }^{1}$ Quanto muito levantam-se-nos dúvidas na definição de interesses legítimos - sendo que essa é uma matéria que deve ser largamente discutida por juristas e em último caso, decidida por Tribunal competente - e ainda relativamente ao que será então a referida "defesa de interesses vitais do titular dos dados". Contudo, em relação ao 'Interesse Vital', estamos em crer, que naturalmente sempre abrangerá, seja numa interpretação restritiva ou extensiva, tudo o que tenha que ver com a "Vida" e a "Saúde" do titular (o doente), ou seja, matéria em relação à qual os médicos terão, à partida, especiais conhecimentos e deveres.

Em relação à identificação dos doentes com o seu nome nos processos e a identificação dos fármacos que Ihes devem ser administrados pelas equipas de enfermagem, considera-se que deverá ser tida alguma cautela com eventuais excessos de zelo que possam prejudicar o mais correto funcionamento dos serviços e, em última análise, colocar em perigo a saúde e quem sabe talvez a vida do doente. $\mathrm{O}$ acesso aos dados dos doentes por parte das equipas médicas e de enfermagem parecem assim enquadrados com a alínea d) do número 1 do artigo $6 .^{\circ}$, que refere a licitude do tratamento dos dados caso seja necessária para a defesa dos interesses vitais do titular dos dados. ${ }^{1}$
Desse modo, a articulação entre as equipas médica e de enfermagem - porventura extensível a outros elementos da equipa assistencial - parece, aos autores, matéria suficiente para justificar que os profissionais envolvidos nesses ambientes específicos tenham acesso aos necessários dados, a fim de evitar fatores de confundimento que possam gerar erros que, na pior das hipóteses, poderão ser mortais (ie. administração de um fármaco ao doente errado, por estarem a ser utilizadas apenas as iniciais dos seus nomes para identificação de processos).

Quanto ao fornecimento de dados do processo (clínico e administrativo) a outras entidades, sobretudo as judiciais, coloca-se a questão do tipo de dados que poderiam ser fornecidos sem consentimento do próprio doente. Aqui, temos necessariamente de separar entre dados clínicos e administrativos, visto serem dois tipos de dados diferentes e acerca dos quais se pode agir de diferente forma.

Quanto à cedência de dados clínicos dos doentes, e mesmo aquando de pedido por entidade judiciária, não nos é claro o motivo pelo qual a vigência do RGDP levantou dúvidas entre os médicos. É que de facto esta realidade não é nova e tal matéria estava já por força de Lei prevista e definida. No nosso país, resulta do artigo $195 .^{\circ}$ do Código Penal $(\mathrm{CP})^{3}$ conjugado com o artigo $135 .^{\circ}$ do Código de Processo Penal (CPP),${ }^{4}$ que não poderá ser fornecido sem consentimento do doente, informação clínica, que é protegida pelo sigilo profissional (Segredo Médico). A divulgação de elementos clínicos contende com a lei em vigor e com tal procedimento o profissional arrisca-se porventura a ser alvo de um procedimento criminal. Naturalmente, deverá sempre ser tido o devido cuidado, uma vez que uma resposta negativa, taxativa, intempestiva e inconforme poderá levar o médico a incorrer em responsabilidade penal por crime de Desobediência, também previsto e definido no artigo $348 .^{\circ}$ do $\mathrm{CP},{ }^{3}$ uma vez que cabe ao Tribunal, e não ao médico, a ponderação dos interesses em jogo e a decisão final.

Na circunstância de um pedido de informação clínica por parte de um Magistrado do Ministério Público (MP), Órgão de Polícia Criminal, ou por exemplo por uma Comissão de Proteção de Crianças e Jovens (CPCJ), deverá o clínico sempre dar uma resposta, porventura esclarecendo que, sem prejuízo do ulterior envio de toda a informação médica solicitada, como seguramente o tribunal compreenderá, teme-se colidir com o disposto nos artigos $195 .^{\circ}$ do $\mathrm{CP}^{3} \mathrm{e}$ $135 .^{\circ}$ do CPP, ${ }^{4}$ necessitando-se do consentimento do doente; pode mesmo o clínico solicitar à entidade que o possa obter, ou, se assim for entendido, solicitar autorização para o próprio médico chamar o doente à sua consulta e obter essa anuência. Este caso exclui, obviamente, os casos nos quais tem de haver quebra do segredo médico por via do princípio do interesse preponderante, decidido por Magistrado Judicial competente. Caso, por exemplo, um Senhor Magistrado do MP, envie por ofício uma insistência - reforçando, mesmo assim, o envio da informação por parte do médico - então deverá de imediato ser obedecido e procedido ao envio dos elementos pedidos, pois tal significa ou 
leva logicamente a presumir, que nos termos legais foi já feita a devida ponderação jurídica dos interesses em jogo, por um Senhor Juiz, e decidido em Despacho, cuja fundamentação (legal) constará do Processo, o levantamento do Sigilo Médico. Também os artigos $29 .^{\circ}$ e seguintes do Regulamento de Deontologia Médica, ${ }^{5}$ se reportam a esta realidade, estando em linha com o supra exposto.

Quanto à cedência de dados pessoais não clínicos dos doentes, importa salientar que, sem prejuízo do cumprimento do expresso no RGDP, é proposto que cada país da União Europeia possa legislar acerca do tratamento de dados de forma mais específica, sendo certo que, tratando-se de solicitação por entidade judicial, ou judiciária, não se deverá levantar qualquer problemática. Atendendo ao artigo $6 .^{\circ}$ do mesmo RGDP que permite o tratamento de dados pessoais quando "for necessário para o cumprimento de uma obrigação jurídica a que o responsável pelo tratamento esteja sujeito" ou "o tratamento for necessário para a defesa de interesses vitais do titular dos dados ou de outra pessoa singular" e ainda na circunstância de "o tratamento for necessário ao exercício de funções de interesse público", parece lógico e consensual o envio do solicitado. ${ }^{1}$

Em Portugal e no que aos médicos diz respeito, deverão sempre ser também considerados aspetos éticos e deontológicos que naturalmente estão sob a alçada da Ordem dos Médicos. Porém, nesta matéria, estamos em crer que o Regulamento de Deontologia Médica (RDM), ${ }^{5}$ publicado em Diário da República no mês de Julho do ano de 2016, se reporta apenas a dados clínicos e não necessariamente também a outros dados pessoais, sobretudo os administrativos. Aqui a dificuldade será perceber, ou interpretar se, independentemente da não conformidade com normas legais, a divulgação de dados administrativos entra em conflito, ou não, com a ética e a deontologia médica. É que, de facto, nem sempre é fácil afirmar se um dado é apenas administrativo ou se ele em si tem já um valor clínico (exemplos de situações de duvidosa classificação quanto à especifica natureza serão o valor de um grau de incapacidade, que é um dado administrativo fundamentado em dados médicos, ou a presença frequente e reiterada numa consulta de uma dada especialidade médica que aponta, pela lógica e experiência comum, para um dado diagnóstico). Assim, se o dado pessoal for tido como clínico, aparentemente, e pelo menos do ponto de vista ético, igualmente não poderá ser cedido sem autorização por escrito do doente titular dos dados, o que está em consonância com o RGDP para toda e qualquer entidade que não seja judicial ou judiciária.

Deste modo, no entender dos autores, e naquilo que concerne dados pessoais (de natureza administrativa), fica claro que estes se poderão fornecer a entidades judiciais ou judiciárias, como é o caso dos Tribunais e MP. Acresce que, caso venha a ser o médico nominalmente chamado para tal, poderá solicitar autorização ou Despacho competente, que no caso poderá ser do Encarregado da Proteção de Dados (EPD) da sua instituição, ou, se assim for entendido - caso haja dúvidas se de dados médicos se trata
- da hierarquia médica responsável, e em última análise do Conselho Diretivo ou em quem este órgão formalmente delegar. Esta postura permitirá uma posição mais asseguradora de Direitos por parte do médico em relação ao doente, protegendo os interesses deste último.

Em relação ao fornecimento de dados a outra entidade com autorização expressa do doente, importa enfatizar, que caso seja solicitada a cedência de dados clínicos, mas exista, por parte deste, um documento que autorize a cedência dos seus dados clínicos para essa finalidade específica, em nada deverá o médico opor-se à realização e envio do devido relatório médico, como explícito no número 3 do artigo $3 .^{\circ}$ da Lei 12/2005. ${ }^{6}$ Do mesmo modo, a consulta do processo clínico pelo doente, a pedido deste, é questão que se coloca com a entrada em vigor do RGPD. Embora sintam os autores que o RGPD veio reforçar a presença deste direito, ele encontra-se devidamente expresso, por exemplo, na Constituição da República Portuguesa, podendo ler-se no artigo $35 .^{\circ}$ número 1 desse documento que todos os cidadãos têm o direito de acesso aos dados informatizados que lhes digam respeito, ${ }^{7}$ bem como, no número 2 do artigo $268 .^{\circ}$, que os cidadãos têm "direito de acesso aos arquivos e registos administrativos...", obviamente sem que tal contenda com segurança, investigação criminal e intimidade das pessoas. Teme-se, no entanto, que esta realidade possa condicionar os registos clínicos efetuados pelos médicos, por terem conhecimento de que os titulares dos dados os poderão requerer, ou que cedam a pedidos de adulteração dos mesmos a pedido dos doentes.

Quanto ao tempo de duração do registo dos dados, esta dependerá do tipo de dados em causa e de quais as suas finalidades, podendo inferir-se pela leitura do artigo 21. números 1) e 2) da Lei 58/2019 de 8 de Agosto que diz que o prazo de conservação de dados pessoais é o que estiver fixado por norma legal ou regulamentar ou, na falta desta, o que se revele necessário para a prossecução da finalidade, referindo ainda que quando a informação em causa concerne fins de interesse público, fins de investigação científica ou histórica ou fins estatísticos, não seja possível determinar antecipadamente o momento em que o mesmo deixa de ser necessário, é lícita a conservação dos dados pessoais. ${ }^{8}$ Mais ainda, refere o mesmo artigo que os casos em que existe um prazo de conservação de dados imposto por lei, só pode ser exercido o direito ao apagamento previsto no artigo $17 .^{\circ}$ do RGPD ${ }^{1}$ findo esse prazo.

Esta informação faz com que considerem os autores como legítima a conservação dos dados clínicos dos doentes em processos médicos devidamente protegidos e designados para essa finalidade, uma vez que os dados clínicos apurados podem ser relevantes em qualquer ponto da vida da pessoa, bem como, depois das devidas autorizações por parte dos Conselhos de Ética dos hospitais e dos doentes, servir finalidades de investigação clínica.

Quanto à necessidade de pedido de autorização por parte do doente para registo de dados pessoais e transmissão entre os vários técnicos de saúde, considera-se, com 
base na Lei 58/2019 de 8 de Agosto, que tal não será necessário, uma vez que, segundo o artigo $30 .^{\circ}$ dessa Lei, os dados relativos à saúde podem ser organizados em bases de dados ou registos centralizados assentes em plataformas únicas quando tratados para efeitos das finalidades legalmente previstas no RGPD e na legislação nacional, desde que esses dados preencham os requisitos de segurança e de inviolabilidade previstos no RGPD. ${ }^{8}$

Pelos dados acima expostos, considera-se que os médicos, quando nomeados por entidades oficiais que visam assuntos de interesse público (tribunal, MP), poderão fornecer dados administrativos relativos aos seus doentes, ainda que sendo prudente remeter previamente os mesmos para a hierarquia clínica (em ultima análise a Direção Clínica, no caso dos Diretores de Serviço), ou para o EPD, conforme o conforme a instituição.

Mais ainda, importa realçar o facto de que, quanto à questão da cedência de dados clínicos sem autorização expressa do doente, nada muda com a entrada em vigor do RGPD. Mantém-se o dever de manter o segredo médico, que não deverá ser quebrado salvo em situações excecionais, nomeadamente as mencionadas no texto.

Ainda consideramos, mesmo para dados meramente

\section{REFERENCIAS}

1. Regulamento (UE) $2016 / 679$ do Parlamento Europeu e do Conselho de 27 de abril de 2016 relativo à proteção das pessoas singulares no que diz respeito ao tratamento de dados pessoais e à livre circulação desses dados e que revoga a Diretiva 95/46/CE (Regulamento Geral sobre a Proteção de Dados). [consultado 2019 set 30]. Disponível em https://eur-lex.europa.eu/legal-content/PT/TXT/PDF/?uri=OJ:L:2016:11 9:FULL\&from=EN.

2. Parecer $N^{\circ} 20 / 2018$ da Comissão Nacional de Proteção de Dados relativa a Proposta de Lei n. ${ }^{\circ}$ 120/XIII. [consultado 2019 set 30]. Disponível em http://app.parlamento.pt/webutils/docs/ doc. pdf? path $=6148523063446 f 764 c 324679626 \mathrm{~d} 56304 \mathrm{c} 334 \mathrm{e}$ 706447567 a 4c31684a53556c4d5a5763765130394e4c7a464 451554 e $45544563765247396 a 6457316$ c626e 527663306 c 7 $561574 \mathrm{e} 7059585270646 \mathrm{~d} 46446232317063334 \mathrm{e} 686279396 a 5 a 57593$ administrativos e para toda e qualquer outra entidade que não o Tribunal ou o seu doente, que o pedido de elementos ao médico assistente não deveria nunca ser solicitado, de forma rotineira ou automática, pelos assistentes técnicos que administrativamente os recebem, a menos que naturalmente esse seja o procedimento normativo regular instituído e escrito. É que, na ausência de Normas Internas explícitas e claras - que o médico enquanto funcionário tenha obrigação de conhecer - é importante que exista um Despacho, da entidade hierárquica ou legalmente competente para o efeito.

\section{AGRADECIMENTOS}

A Peter Villax, que ajudou a clarificar a área de abordagem que seria adequada à elaboração do presente artigo.

\section{CONFLITOS DE INTERESSE}

Os autores não têm quaisquer conflitos de interesse.

\section{FINANCIAMENTO}

Não foi necessário financiamento por entidades externas.

359544d794f4330325a44526c4c54526c4e546b74596a41304e433169 4 e54426d4f5449314d6a64684d7a45756347526d\&fich=cef7a328-6d4e -4e59-b044-b50f92527a31.pdf\&Inline=true

3. Código Penal Português. Lei $n^{\circ} 102 / 2019$ de 6 de junho. $49^{a}$ ed. Lisboa.

4. Código de Processo Penal. Lei n. ${ }^{\circ} 102 / 2019$, de 06 de setembro. $42^{a}$ ed. Lisboa.

5. Ordem dos Médicos. Regulamento de Deontologia Médica n. ${ }^{\circ} 707 / 2016$. Diário da República, II série, N. ${ }^{\circ} 139$ (21/07/2016). p.22575-88.

6. Decreto-Lei n 12/2005. Diário da República, I Série, n 18 (26/01/2005). p.606-11.

7. Assembleia da República. Sétima Revisão Constitucional. Diário da república, I Série, nº 155 (12/08/2005). p.4642-86.

8. Decreto-Lei n 58/2019. Diário da república, I Série, nº 151 (08/08/2019). p.3-40. 